\title{
Including both equity and efficiency claims for international development
}

\section{Cheryl R. Doss}

(forthcoming, Canadian Journal of Development Studies)

What justifications should be used for public policies that aim to promote women's equality? Should these policies be grounded on claims about the intrinsic worth of women? Or are the justifications more persuasive if they are based on claims of efficiency? Debates about the benefits and pitfalls of efficiency have been around for many years. This has been particularly true in the field of international development, where scrutiny of expenditures is particularly high because of the political sensitivity of transferring money from taxpayers in one country to citizens of other countries. Are policies promoting women's equality a worthwhile use of development funds? The questions are not new, but in recent years, the context has changed in some substantive ways, and it is useful to consider some new elements.

Particularly in the arena of international development, there is increasing use of efficiency claims to make the case for including women in the process of economic growth and development. The FAO flagship report State of Food and Agriculture for 2010-11 claims, "If women had the same access to productive resources as men, they could increase yields on their farms by 20-30 percent. This could raise total agricultural output in developing countries by 2.54 percent, which could in turn reduce the number of hungry people in the world by 12-17 percent.” (FAO, p. 5). Along the same lines, the World Bank’s 2012 World Development Report begins “Gender equality is a core development objective in its own right.” But this early appeal to an equality argument is immediately followed by an efficiency argument - which then sets the tone for the remainder of the report: "It is also smart economics. Greater gender equality can enhance productivity, improve development outcomes for the next generation, and make 
institutions more representative” (World Bank 2011, p. xx). Moving beyond the international development sector, The McKinsey Global Institute used an efficiency argument as the basis for promoting gender equality in their 2012 publication, The power of parity: How advancing women's equality can add \$12 trillion to global growth. All three of these publications are thus making claims that increasing women's equality will result in desirable outcomes, in terms of economic growth and development.

A related rhetoric has been taken up by the corporate sector. The Coca Cola Foundation’s $5 \times 20$ campaign has the goal of empowering five million women by 2020. The Wal-Mart Foundation similarly has a Global Women’s Economic Empowerment Initiative. These groups are not necessarily talking about women's equality, but about women’s empowerment, defined fairly imprecisely. In 1999, Kabeer defined empowerment as "the processes by which those who have been denied the ability to make choices acquire such an ability” (p. 437). These corporate empowerment initiatives have a somewhat narrower agenda; they are designed to increase women's income and their control over income, so that they can better participate in markets. They promote women’s market participation, but do not usually directly challenge the structural limitations, such as discriminatory institutions and social norms, that limit women’s equality. For the past 15-20 years, the donor community for international development has explicitly subscribed to a rhetoric that affirms the importance of gender equality. Essentially all the major development donors embrace the idea that aid programs should target women and incorporate gender issues into programs and policies. These programs typically expect to achieve good outcomes through one of two main pathways. First, incorporating women into the programs may directly result in growth and development. Second, incorporating women into 
programs may result in increased gender equality, and as noted above, this is expected to result in economic growth and development.

Yet, in spite of this rhetoric, gender equality is seldom identified as an explicit goal for development programs. In part, this reflects lingering inertia -- and occasionally outright resistance -- to targeting women. It would not be easy for development agencies to design programs that will bring about women's equality; this kind of social change is far more complicated than the typical development intervention.

In practice, what often happens, especially in the area of agricultural development, is that projects are designed and then, because the donors insist that gender be included, gender issues are simply tacked on at the end. Proposals are thus full of phrases such as, “... and we will target women and other marginalized groups," or identifying project beneficiaries, noting "half of whom will be women.” This emphasis on “women as half of the beneficiaries” is not intrinsically bad; but is not the same as a focus on women’s equality. For a start, an equality focus would require identifying the immediate objectives and constraints that face women - and rethinking development projects to target these challenges. If such projects were implemented, they would also identify the This suggests that there is still vast scope for project implementers to understand the benefits of incorporating women into the projects. But even this does not speak to the-social and structural issues that may pose deeper obstacles to achieving gender equality.

A steadily growing body of research, however, has begun to analyze gender issues in development with more rigorous methods and better data. This research shows that promoting women's equality is not always a simple win-win situation. For example, a recent set of papers analyzing women’s agricultural productivity finds two different sets of reasons why women farmers have lower agricultural productivity on their plots than men (Aguilar et al 2015; Yetna et 
al 2015; de la O Campos et al 2016; Kilic et al 2015; Oseni et al 2015; Slavchevska 2015). One reason for their low productivity is that women farmers typically have less access to essential inputs for farming; e.g., cash or credit to purchase seeds or fertilizer. They may also lack access to information or extension services, and they often farm poorer quality land. The research consistently finds that increasing women's access to these inputs would increase their productivity. Yet these studies also find a second reason for the low productivity of women farmers - which is that in many contexts, women farmers obtain lower returns than men to the inputs that they do use. There are many possible explanations: women farmers face many other constraints, such as the burdens of responsibility for household and caring activities, or their limited access to markets. The analyses suggest a number of potential interventions that could increase the productivity of women farmers. But the efficiency argument for targeting agricultural development to women does not always hold. If women farmers obtain lower returns than men from to-the same inputs, providing those inputs to men might plausibly result in higher overall agricultural productivity at least in some domains.

Another dimension that is changing is the increasing availability of sex-disaggregated data that can be used to analyze various aspects of the efficiency claims, such as the nationally representative surveys used to consider the gender gap in agricultural productivity. While the goal of all countries routinely collecting sex-disaggregated data remains elusive, numerous efforts are currently underway to improve both the quality and quantity of data. There is increasing recognition, for example, that women's rights over land and other assets are important and that detailed data are needed to track the effectiveness of efforts to increase women's claims.

Better data are needed to empirically identify the situations in which women's equality actually does result in efficiency gains. And better data may help us to develop programs and 
policies that promote women's equality. Yet, we need also to be cognizant of the times when analyses of these new detailed data may find outcomes that are not consistent with a win-win perspective. supportive of promoting women's equality. They may identify costs and trade-offs that were not anticipated.

Some of these costs may simply reflect short-run adjustments. For example, agricultural extension programs may need to be redesigned if they are to reach women farmers in effective ways. There may be costs to this restructuring and reimagining, even if there are net benefits in the end. But other costs may be more significant and potentially undermine any efficiency gains; for example, some of the resources and power held by men will have to be shared in order for women to gain equality; we cannot expect that gender equality will always leave everyone better off. Men may have to give up land in order for women to obtain it. And there may even be efficiency losses, as pointed out above, as achieving equality may not always be compatible with the highest levels of productivity. It is important to understand when there are trade-offs between equity and efficiency and when they are complementary.

When there are trade-offs, it is necessary to appeal to other reasoning for why it is important to support women farmers. For instance, a modified instrumentalist argument might hold that moving toward gender equality in the access to resources is an effective way to reach poor women and to reduce poverty, improve well-being of women and their children, even if it does not necessarily result in higher total productivity. This is still an instrumentalist approach, but with an appeal to a different goal.

The efficiency arguments for women's equality are powerful and have changed some of the rhetoric regarding women, especially in the context of development. Yet, if we rely only on these arguments, there will be times when the efficiency arguments may work against women's 
equality. The potential trade off between equity and efficiency suggests that, in addition to using efficiency arguments when appropriate, it is also time to reclaim the moral arguments for women's equality.

Moral arguments are used - and should be used explicitly -- in the discussions about poverty and inequality, and should be used more broadly in the discussions of gender equality. along with the more instrumentalist claims. As a matter of justice, women should have the same rights to land as men, and these rights should be reflected in the land laws and the marriage and inheritance laws. Women farmers should have the same rights to other productive resources as men; when these resources are provided by the state, they should be available to both men and women.

Finally, it is perhaps also the time to refocus turn the focus to on structural sources of inequality, rather than to simplistic metrics of "women as beneficiaries" from programs that have little or no emphasis on redressing gender imbalances. Too many development projects define their gender targets in terms of making women equal beneficiaries in the programs; it is perhaps time to set more ambitious goals in terms of gender equality. The current approaches, as embodied in many development projects, cannot change the structures that continue to provide women with less voice and fewer opportunities relative to men.

The efficiency claims must be paired with strong moral claims for women’s rights and equality. Women have the right to equality, and this remains true whether or not there are also efficiency gains from programs that target women.

\section{References}


Aguilar, A., Carranza, E., Goldstein, M., Kilic, T., \& Oseni, G. (2015). Decomposition of gender differentials in agricultural productivity in Ethiopia. Agricultural Economics, 46(3), 311334. http://doi.org/10.1111/agec.12167

Allendorf, K. (2007). Do Women's Land Rights Promote Empowerment and Child Health in Nepal? World Development, 35(11), 1975-1988.

http://doi.org/10.1016/j.worlddev.2006.12.005

Backiny-Yetna, P., \& McGee, K. (2015). Gender Differentials and Agricultural Productivity in Niger (Policy Research Working Paper No. 7199). Washington D.C.

De la O Campos, A.P., Covarrubias, K. A., \& Patron, A. P. (2016). How Does the Choice of the Gender Indicator Affect the Analysis of Gender Differences in Agricultural Productivity? Evidence from Uganda. World Development, 77, 17-33. http://doi.org/10.1016/j.worlddev.2015.08.008

Doss, C. (2013). Intrahousehold Bargaining and Resource Allocation in Developing Countries. The World Bank Research Observer, 28(1), 52-78. http://doi.org/10.1093/wbro/lkt001

Doss, C. (2006). The effects of intrahousehold property ownership on expenditure patterns in Ghana. Journal of African Economies, 15(01), 149-180. http://doi.org/10.1093/jae/eji025

Food and Agriculture Organization (FAO). 2011. The state of food and agriculture: Women in agriculture: Closing the gender gap for development. Rome: FAO.

Kabeer, N. (1999). Resources, Agency, Achievements: Reflections on the Measurement of Women's Empowerment. Development and Change, 30(3), 435-464. http://doi.org/10.1111/1467-7660.00125

Kilic, T., Palacios-López, A., \& Goldstein, M. (2015). Caught in a Productivity Trap: A Distributional Perspective on Gender Differences in Malawian Agriculture. World Development, 70, 416-473. http://doi.org/10.1016/j.worlddev.2014.06.017

Oseni, G., Corral, P., Goldstein, M., \& Winters, P. (2015). Explaining gender differentials in agricultural production in Nigeria. Agricultural Economics, 46(3), 285-310. http://doi.org/10.1111/agec.12166

Panda, P., \& Agarwal, B. 2005. Marital violence, human development and women's property status in India. World Development, 33(5), 823-850. http://doi.org/10.1016/j.worlddev.2005.01.009

Slavchevska, V. (2015). Gender differences in agricultural productivity: the case of Tanzania. Agricultural Economics, 46(3), 335-355. http://doi.org/10.1111/agec.12168

World Bank. 2011. World development report 2012: Gender equality and development. Washington DC: World Bank 
